\title{
SHORT-TERM PERFORMANCE, ASYMMETRIC INFORMATION AND INEFFICIENT CORPORATE DECISIONS
}

\author{
Jorge Fernández Ruiz* \\ Centro de Estudios Económicos, El Colegio de México, A. C.
}

(Received 12 january 2002, accepted 8 march 2002)

\begin{abstract}
We analyze a model in which a firm raises funds from asymmetrically informed investors. The firm's short-term performance may alleviate this adverse selection problem, but it may also give incentives for inefficient behavior. We study the equilibrium behavior resulting from the interplay of these effects.
\end{abstract}

\section{Resumen}

En este artículo se analiza un modelo en el que una empresa obtiene financiamiento en condiciones de información asimétrica. El desempeño de corto plazo de la empresa puede mitigar este problema de selección adversa, pero a costa de dar incentivos para llevar a cabo acciones ineficientes. Se estudia el comportamiento de equilibrio que resulta de la interacción de estos dos efectos.

JEL Classification: G32, G33.

Keywords: Short-term signals, adverse selection.

* Centro de Estudios Económicos, El Colegio de México A. C., Camino al Ajusco 20, 10740 México, D. F., Teléfono (52) 54493000, E-mail: jfernan@colmex.mx.

The author wishes to thank two anonymous referees for helpful comments. 


\section{Introduction}

Although according to traditional financial theory, competitive financial markets give firms the incentives to undertake the best available projects and devote resources to the best available uses, there is some concern that financial markets irrationally prefer short-term results. According to this view, firms that have to rely on outside financing are pressed by the market to obtain quick results, giving rise to a "short-term" economy". These firms may take actions that do not increase net present value if they boost their short-term performance.

In this paper, we present a model in which asymmetric information in financial markets may lead firms to take actions that improve their short-term performance even though they do not increase their net present value. In the basic model, which is a variation of Diamond $(1991,1993)$, a firm has to rely on outside financing to undertake a project. Financial markets do not know the quality of the firm's project, which is the firm's private information. 'Yet, during the course of the project, the firm's performance is observed by financial markets, who can, thus, enhance their knowledge about the project's quality. Following Diamond, we show that under these circumstances, the equilibrium financial contract may imply liquidating the project if short-term performance is bad. Firms with good projects accept this contract because they are confident that their short-term performance will show that their projects are indeed good, and that this will allow them to refinance at better terms. Yet, this financial contract may give incentives to distort the firm's behavior so as to ensure good short-term results, even if this is not optimal when taking a long-term perspective. We show that the financial contract may need to be modified to avoid this type of behavior. There is a trade-off between modifying the financial contract to avoid "short-termism", and not modifying it and inducing costly actions that do not improve net present value. We show that depending on the relative importance of these forces, the equilibrium may or may not involve the firm taking actions that boost short-term results even though they do not maximize net present value.

To explain the place of this paper in the literature, let us mention its main differences with related contributions. In a seminal paper, Stein (1989) shows that managers seeking to increase a firm's stock value may behave myopically. To do this, Stein relies on an exogenously defined objective function for managers: It is posited that managers care both about long-run earnings and current stock prices, with the weight given to each of these objectives being exogenously set. Garvey, Grant and King (1999) argue that the managers' concern for short-term stock prices should not be exogenously imposed, but rather be shown to be the result of optimal decisions on the part of shareholders. This is exactly what they do: they show that when shareholders are free to set the managers' compensation scheme, they link the managers' pay to the short-term stock price, and "short-termism" may still occur. Both of these papers start from the existence of managerial incentive problems. The difference of our model with these two papers is that we do not rely on the existence of

\footnotetext{
1 See, for instance, Jacobs' (1993) Short-Term America.
} 
these problems: there are no incentive problems that need to be dealt with in the first place.

On the other hand, in Von Thadden (1995) and Webb (1993), entrepreneurs have to choose one of two mutually exclusive projects with different gestation poriods, and it is shown that there is a bias for short-term projects. In contrast, in our model there is no such choice. Our paper thus shows the emergence of short-termism without having to rely on either the existence of managerial incentive problems or the choice between mutually exclusive projects with different gestation periods. Short-termism arises simply as an attempt of informed firms to convey early information to uninformed investors in an environment without project selection or managerial incentive problems.

The rest of the paper is organized as follows. Section 2 presents the basic model. Section 3 derives the optimal financial contract without considering the possibility of the firm taking actions that improve its short-term performance. This possibility is introduced in section 4, in which the trade-off originated by the existence of actions that boost short-term performance is analyzed. Section 5 concludes.

\section{The Model}

In this section, we present the basic model, which is a variation of Diamond (1991, 1993). In this model, a firm lacks the funds to undertake a project, and has private information about the quality of this project. Before the project matures, news will arrive reducing the asymmetry of information between the firm and its investors.

\subsection{The Project and the timing}

A firm must raise outside finance to undertake a project whose life extends over three periods, $t=0,1,2$. At $t=0$, the amount $I$ is raised and invested in the project. This amount is raised in a competitive credit market through a financial contract that provides nonnegative expected returns to investors. At $t=1$, a signal about the quality of the project is realized and observed by both the firm and its investors. After this signal becomes known, the firm may be liquidated, which results in investors obtaining an amount $L<I$. At $t=2$, the project matures and produces income ${ }^{2}$. With this timing, we capture the fact that during the life time of the project, before it matures, new information arrives allowing investors to update their initial beliefs about the quality of the project. This new information can be used to decide whether to stop the project or complete it. There are two types of projects, good and bad. The type of the project is a firm's private information. A firm with a good project obtains an income of $X>I$ at $t=2$, while a firm with a bad project obtains

2 In Diamond (1991, 1993), all projects also produce a "control" rent at $t=2$, which accrues to the borrower - and is not transferable - if there is no cancelation at $t=1$. Including this rent would complicate matters without altering our results. 
$X$ with probability $\pi$ and 0 otherwise, with $\pi X<I$. Thus, under symmetric information, bad projects would not obtain financing. But, we assume that investors do not know if a project is good or bad. At date-zero, they assign the firm a probability $f$ for having a good project. Therefore, there is a probability $q=f+(1-f) \pi$ that the firm's date-two income will be $X$. The project can be liquidated before it matures, in such a case, investors receive $L<I$ at date $t=2$, whether it is good or bad.

News arriving at date-one refer to the short-term performance of the project and can be good, $s=u$ (an upgrade of the firm's rating takes place), or bad, $s=d$ (a downgrade takes place). Bad borrowers receive bad news for sure. Yet, this intermediate signal is not perfect, since good borrowers may receive bad news too. We assume that they do with probability $e<1$. After observing the realization of event $s$, investors update their beliefs about the quality of the project. They do this by applying Bayes' rule. Let $f^{d}\left(f^{u}\right)$ be the updated probability, according to Bayes' rule, that the project is good given bad (good) news. We have:

$$
f^{d}=\frac{e f}{f e+(1-f)}
$$

and

$$
f^{u}=1 \text {. }
$$

Likewise, denote by $q^{d}\left(q^{u}\right)$ the conditional probability that date-two income, if there is no adjustment, will be $X$ given bad (good) news.

\section{Optimal Financial Contracts}

The financial contract signed at date-zero specifies the probability of liquidation both after bad and good news, $\phi^{d}$ and $\phi^{u}$, respectively, and the repayments that the firm has to make if it is not liquidated also after bad and good news, $R^{d}$ and $R^{u}$, respectively. We will focus, as Flannery (1986) and Diamond (1991, 1993) do, on the contract preferred by good quality borrowers among the pooling equilibrium contracts. This means that we will study a situation in which all firms offer the same contract, which is the one preferred by good quality firms among those able to attract financing. Thus, the optimal contract chooses $\left(\phi^{d}\right.$, $\left.\phi^{u}, R^{d}, R^{u}\right)$ so as to solve:

Program (1):

$$
\text { Maximize } H=e\left(1-\phi^{d}\right)\left(X-R^{d}\right)+(1-e)\left(1-\phi^{u}\right)\left(X-R^{u}\right)
$$

subject to:

$$
[f e+(1-f)]\left[\left(1-\phi^{d}\right)\left(q^{d} R^{d}\right)+\phi^{d} L\right]+f(1-e)\left[\left(1-\phi^{u}\right) R^{u}+\phi^{u} L\right] \geq I,
$$

and

$$
0 \leq R^{d} \leq X, \quad 0 \leq R^{u} \leq X, \quad 0 \leq \phi^{d} \leq 1, \quad 0 \leq \phi^{u} \leq 1 .
$$

Let us interpret this program. Constraint (3) establishes that the contract is profitable for investors. With probability $f e+(1-f)$ there is bad news about 
the project $(s=d)$. In such a case, the project survives with probability $1-\phi^{d}$, in which case investors obtain an expected repayment of $q^{d} R^{d}$. On the other hand, the project is liquidated with probability $\phi^{d}$ and investors get $L$. The second term in the left-hand side of constraint (3) has a similar interpretation: with probability $f(1-e)$ there is good news. After good news, the project survives with probability $1-\phi^{u}$ and investors receive $R^{u}$, and the project does not survive with probability $\phi^{u}$ and investors get, say, $L^{u}$.

The objective function is a good firm's expected income (net of repayments to investors). With probability $e$ there is bad news, and the firm retains an amount $X-R^{d}$ if the project survives, which occurs with probability $1-\phi^{d}$. With probability $1-e$ there is good news. In this case, the firm survives with probability $1-\phi^{u}$, and then gets a net income of $X-R^{u}$.

Given the existence of limited liability, if the firm is able to attract financing it will find in its interest to undertake the project. To attract financing, the firm must find a contract that satisfies the constraints of the above program. To see if such a contract exists, set first scheduled repayments at their maximum level, $R^{d}=R^{u}=X$. Set then null liquidation of the project after good news, $\phi^{u}=0$. We can do this because if it were optimal to liquidate the project even after good news, the project would surely not attract funds (because $L<I$ ). Maximizing, now, the returns to investors, the left-hand side of (3) with respect to $\phi^{d}$, we obtain that the project will attract financing if

$$
\operatorname{Max}\{[f e+(1-f)] L+f(1-e) X, q X\}>I
$$

The first term in the maximand obtains when the firm's project is adjusted after bad news $\left(\phi^{d}=1\right)$ : with probability $f e+(1-f)$, bad news will indeed occur, in which case the project will be liquidated and repayment will equal $L$. With probability $f(1-e)$, there will be good news and the project will be completed and yield repayments of $X$. The second term in the maximand, $q X$, obtains when the project is always completed, no matter what date-one news is received. Notice that, even if $q X<I$, the project may still attract financing. In this case, the project would yield an expected negative return if carried out to its full completion regardless of date-one news. But, if the project is liquidated after bad news and completed only if there is good date-one news, it will have a positive net present value.

The following proposition (whose proof is in the appendix) is a slight variation of Diamond $(1991,1993)$, and characterizes the optimal financial contract.

Proposition 1. Assume that the firm's project can attract financing. Then, the optimal financial contract establishes that:

i) If there is good date-one news, the project is completed $\left(\phi^{u *}=0\right)$, and the firm repays less than its cash flow $\left(R^{u *}<X\right)$.

ii)If there is bad date-one news and $q^{d} X<L$, the project is liquidated $\left(\phi^{d *}=1\right)$. 
To interpret the condition $q^{d} X<L$, notice that $q^{d}$ is an increasing function of $e$, and that $q^{d} X<L$ will hold if $e$ is small enough, that is, if the probability that a good firm obtains a bad short-term signal is low enough. Thus, assertion ii) in proposition 1 will hold whenever the short-term signal is accurate enough.

To take advantage of an accurate short-term signal, the optimal contract liquidates the project if this signal is bad. Firms with good projects accept this contract because the risk of their projects being liquidated is more than offset by the reduction in their financing costs. This reduction takes place because bad projects yield higher returns when they are liquidated than when they are completed, and the increase in repayments from bad projects translates into lower repayments from good projects.

\section{Short-Termism}

We now consider the possibility that the firm engages in short-termism. "By this, we mean that the firm takes actions that boost its short-term performance without enhancing its net present value. Although these activities do not create value, a contract that threats to liquidate the firm if its short-term performance is poor, creating incentives for the firm to devote resources to them and reduce the likelihood of liquidation.

We assume that the firm can take an action (at cost $c>0$ ) that reduces the probability of a bad signal to $e^{S}<e$. The firm will engage in short-termism if:

$$
\begin{gathered}
e^{S}\left(1-\phi^{d}\right)\left(X-R^{d}\right)+\left(1-e^{S}\right)\left(1-\phi^{u}\right)\left(X-R^{u}\right)-c> \\
e\left(1-\phi^{d}\right)\left(X-R^{d}\right)+(1-e)\left(1-\phi^{u}\right)\left(X-R^{u}\right),
\end{gathered}
$$

which can be written as

$$
\left(e-e^{S}\right)\left[\left(1-\phi^{u}\right)\left(X-R^{u}\right)-\left(1-\phi^{d}\right)\left(X-R^{d}\right)\right]>c .
$$

Replacing the optimal values from proposition one, this amounts to

$$
\left(e-e^{S}\right)\left(X-R^{u *}\right)>c,
$$

or

$$
\left(e-e^{S}\right)\left(X-\frac{I-(f e+1-f) L}{f(1-e)}\right)>c .
$$

Thus, the optimal financial contract induces short-termism if and only if (5) holds.

\subsection{Taking into account short-termism}

We will assume in the rest of this paper that (5) holds, so that the optimal financial contract that ignores the manipulation of the signal by the firm would indeed induce the firm to engage in short-termism. 
We now derive the optimal financial contract taking into account that the contract signed at date-zero may induce the firm to engage in activities that improve its short-term performance without increasing its net present value. After the financial contract has been signed and before the short-term signal is realized, the firm may engage in short-termism, which reduces the likelihood of a bad signal from $e$ to $e^{S}$.

We first find the optimal financial contract within the class of contracts that avoid short-termism. This contract chooses $\phi^{d}, R^{d}, \phi^{u}$, and $R^{u}$, so as to solve

Program (2):

$$
\text { Maximize } H\left(\phi^{d}, R^{d}, \phi^{u}, R^{u}\right)
$$

subject to:

$$
\left.[f e+(1-f)]\left[\left(1-\phi^{d}\right)\left(q^{d} R^{d}\right)+\phi^{d} L\right)\right]+f(1-e)\left[\left(1-\phi^{u}\right) R^{u}+\phi^{u} L\right] \geq I,
$$

and

$$
\left(e-e^{S}\right)\left[\left(1-\phi^{u}\right)\left(X-R^{u}\right)-\left(1-\phi^{d}\right)\left(X-R^{d}\right)\right] \leq c .
$$

This program is equal to program (1), except for the extra constraint (6). This constraint specifies that the benefits from engaging in short-termism are smaller than its costs.

Proposition 2. Let $\left(\phi^{d N S}, R^{d N S}, \phi^{u N S}, R^{u N S}\right)$ be the financial contract that optimally avoids short-termism. This contract:

i) sets survival after good news $\left(\phi^{u N S}=0\right)$,

ii) reduces liquidation after bad news $\left(\phi^{d N S}<1\right)$, and

iii) increases repayments after good news $\left(R^{u N S}>R^{u *}\right)$.

To avoid short-termism, the difference between the profits the firm is entitled to retain after good and bad news needs to be reduced. This is optimally achieved by reducing liquidation after bad news and increasing the repayment due to $R^{u}$ after good news. It is also worth mentioning that the repayments after bad news, $R^{d}$, which were irrelevant in the previous section because the firm was liquidated after such news, do play a role now. They are optimally set equal to zero $\left(R^{d N S}=0\right)$.

Proposition 2 tells us what the optimal contract looks like when the firm decides to commit itself not to engage in short-termism. The next proposition tells us that this may or may not be optimal.

Proposition 3. For each value $e^{S}<e$, there exists $c^{*}$ such that the optimal financial contract:

i) avoids short-termism when $c>c^{*}$, and

ii) induces short-termism when $c<c^{*}$. 
It is useful to illustrate the above proposition by considering two polar cases. Suppose, first, that $c=0$, which captures a situation where the firm can boost its short-term performance at almost no cost. In this case, it is optimal for the firm to engage in short-termism. Consider instead the case in which $c$ is so big that the "no short-termism" constraint is barely violated for the values $\phi^{d *}, R^{d *}, \phi^{u *}, R^{u *}$, that is, if we replace $c$ with $c+\epsilon$, with $\epsilon$ "small", the "no short-termism" constraint holds. In this case, a mild adjustment in the terms of the financial contract avoids short-termism. This causes the avoidance to be optimal.

\section{Conclusions}

In this paper we have developed a formal model to address the concern that firms that rely on outside financing may take actions that produce quick results, irrespective of their impact on net present value. Traditional financial economics holds that firms should care only about net present value; not about when returns are obtained during the life of a project. It also holds that undertaking actions with the sole purpose of improving short-term performance is pointless, since a firm will not be able to fool the market. On the contrary, if these actions reduce the firm's net present value, the market will punish -instead of rewarding - the firm.

A popular view is that, in any case, the so-called "short-termism" could result from a misalignment between firm's long-term interests, and managerial incentives. According to this view, the problem would be solved by giving managers the right incentives. For instance, Jensen (1986) holds that this problem could be solved by having managers holding enough stock in their companies. Indeed, he points out that short-termism occurs "when managers hold little stock in their companies and are compensated in ways that motivate them to take actions that increase accounting earnings rather than the value of the firm. It also occurs when managers make mistakes because they do not understand the forces that determine stock values" 3

We have developed a model that does not rely on any misalignment between firm's long-term interests and managerial incentives. In this model, we have first shown that, when there is asymmetric information in financial markets, optimal financial contracting may involve stopping a project before it matures if there are signals indicating that the project is bad. Although this financial contract alleviates the adverse selection problem, it may also induce an excessive preference for short-term results. We have then derived the optimal financial contract that takes into account this preference, and analyzed the trade-off that it has to faced. Finally, we have demonstrated that, depending of the relative importance of the two forces at work, the equilibrium contract may or may not involve the firm taking actions that boost short-term results but do not maximize net present value.

\footnotetext{
3 See Jensen (1986), p. 11.
} 


\section{Appendix}

\section{Proof of Proposition 1.}

The optimal financial contract chooses $\phi^{d}, \phi^{u}, R^{d}$ and $R^{u}$, so as to solve Program (1):

$$
\text { Maximize } H=e\left(1-\phi^{d}\right)\left(X-R^{d}\right)+(1-e)\left(1-\phi^{u}\right)\left(X-R^{u}\right)
$$

subject to:

$$
\left.[f e+(1-f)]\left[\left(1-\phi^{d}\right)\left(q^{d} R^{d}\right)+\phi^{d} L\right)\right]+f(1-e)\left[\left(1-\phi^{u}\right) R^{u}+\phi^{u} L\right] \geq I,
$$

and

$$
0 \leq R^{d} \leq X, \quad 0 \leq R^{u} \leq X, \quad 0 \leq \phi^{d} \leq 1, \quad 0 \leq \phi^{u} \leq 1 .
$$

At an optimum, (3) holds with equality. Otherwise, we could decrease either $R^{d}$ or $R^{u}$, still satisfy this constraint, and improve the objective function. Solve then for $R^{u}$ in (3), when it holds with equality, as a function of $R^{d}, \phi^{d}$, and $\phi^{u}$. Replace it in the objective function and ignore constraint (3). Call the new objective function $V(\cdot)$. We have that

$$
\frac{\partial V}{\partial R^{d}}>\left(1-\phi^{d}\right)\left(\frac{\pi(1-f)}{f}\right)>0,
$$

and thus $R^{d}=X$ is optimal. Also, $\phi^{u}=0$ is optimal, as

$$
\frac{\partial V}{\partial \phi^{u}}=(1-e)(-X+L)<0,
$$

since $X>L$ (otherwise, the project would not attract financing). Finally, the derivative with respect to $\phi^{d}$ is

$$
\frac{\partial V}{\partial \phi^{d}}=\frac{f e+1-f}{f}\left(L-q^{d} X\right),
$$

which has the same sign as $L-q^{d} X$. Also notice, for future reference, that expected rents for good quality firms decrease in $e$, since

$$
\frac{\partial V}{\partial e}=\phi^{d}(L-X)<0 .
$$

\section{Proof of Proposition 2.}

The optimal contract within the class of contracts that avoids short-termism solves Program (2):

$$
\text { Maximize } V\left(\phi^{d}, R^{d}, \phi^{u}\right)
$$


subject to:

$$
\left(e-e^{S}\right)\left[\left(1-\phi^{u}\right)\left(X-R^{u}\right)-\left(1-\phi^{d}\right)\left(X-R^{d}\right)\right] \leq c .
$$

Notice, first, that constraint (6) is binding because, from proposition 1, ignoring it leads to $\phi^{d}=1, \phi^{u}=0$, and

$$
R^{u}=\frac{I-(f e+1-f) L}{f(1-e)}
$$

a configuration of values for which (6) does not hold. Now, since:

i) a marginal decrease in $\phi^{u}$ raises $V$ by $(1-e) /\left(e-e^{S}\right)$ times the amount it decreases the left hand-side of (6),

ii) a marginal increase in $R^{d}$ raises $V$ by

$$
\frac{\pi(1-f)(1-e)}{\left(e-e^{S}\right)[f+(1-f)(1-e)]}
$$

times the amount it raises the left hand-side of (6), and

$$
\frac{1-e}{e-e^{S}}>\frac{\pi(1-f)(1-e)}{\left(e-e^{S}\right)[f+(1-f)(1-e)]}
$$

then it is optimal to set either $R^{d}=0$ or $\phi^{u}=1$. Suppose for a moment that $\phi^{u}=1$. Since (6) holds with equality, this implies that $\left(1-\phi^{d}\right)\left(X-R^{d}\right)=0$ and thus $V=0$, which is clearly not optimal. Thus, $R^{d}=0$ is optimal. Now, since:

iv) a marginal increase in $\phi^{d}$ raises $V$ by

$$
\frac{e\left(R^{d}-X\right)+(1-e)[f e+(1-f)]\left[L-q^{d} R^{d}\right]}{\left(e-e^{S}\right)[f e+(1-f)]\left[L-q^{d} R^{d}\right]+f(1-e)\left(X-R^{d}\right)}
$$

times the amount it raises the left hand-side of (6), and

$v) \quad \frac{e\left(R^{d}-X\right)+(1-e)[f e+(1-f)]\left[L-q^{d} R^{d}\right]}{\left(e-e^{S}\right)[f e+(1-f)]\left[L-q^{d} R^{d}\right]+f(1-e)\left(X-R^{d}\right)}<\frac{(1-e)}{\left(e-e^{S}\right)}$

then it is optimal to set $\phi^{u}=0$. Thus, the optimal contract within the class of contracts that avoids short-termism satisfies $R^{d}=0, \phi^{u}=0$ and $\phi^{d}$ and $R^{u}$ such that constraints (3) and (6) hold with equality.

\section{Proof of Proposition 3.}

i) The value of the objective function when short-termism is avoided, $V^{N S}$, increases in the cost of engaging in short-termism, $c$. 
ii) The value of the objective function when there is short-termism,

$$
V^{S}=\left(1-e^{S}\right)\left(X-\frac{I-\left(f e^{S}+1-f\right) L}{f\left(1-e^{S}\right)}\right)-c
$$

decreases in $c$.

iii) When $c=0, V^{S}>V^{N S}$. This is because, on the one hand, $V^{S}$ decreases in $e^{S}$ and $e^{S}<e$, and, on the other hand, when $c=0$ and $e=e^{S}, V^{N S}$ results from the same maximization problem that $V^{S}$ with one additional constraint.

$i v$ ) It is straightforward to show that, when $c$ is such that (6) holds with equality, $V^{S}<V^{N S}$. Proposition 3 follows from facts $i$ ) $-i v$ ).

\section{References}

Diamond, D. W. (1991). Debt Maturity Structure and Liquidity Risk. Quarterly Journal of Economics, 106, pp. 709-737.

(1993). Bank Loan Maturity and Priority when Borrowers can Refinance. In Mayer, C. and X. Vives (Eds.). Capital Markets and Financial Intermediation. Cambridge University Press.

Flannery, M. J. (1986). Asymmetric Information and Risky Debt Maturity Choice, Journal of Finance, 41 , pp. 19-38.

Garvey, G. T., S. Grant and S. P. King (1999). Myopic Corporate Behavior with Optimal Management Incentives, Journal of Industrial Economics, 47, pp. 231-250.

Jacobs, M. T. (1993). Short-Term America, Harvard Business School Press, Cambridge, Mass.

Jensen (1986). The Takeover Controversy: Analysis and Evidence. Midland Corporate Finance Journal, 4, pp. 6-32.

Stein, J. C. (1989). Efficient Capital Markets, Inefficient Firms: A Model of Myopic Corporate Behavior, Quarterly Journal of. Economics, 104 , pp. 655-668.

Von Thadden, E. (1995). Long-Term Contracts, Short-Term Investment and Monitoring. Review of Economic Studies, 62, pp. 557-575.

Webb, D. C. (1993). The Trade-Off between Cash Flow and Net Present Value. Scandinavian Journal of Economics, 95(1), pp. 65-75. 